Prepared for the U.S. Department of Energy under Contract DE-AC05-76RL01830

\title{
Low Probability Tail Event Analysis and Mitigation in the BPA Control Area: Task 1 Report
}

S Lu

YV Makarov

April 2009

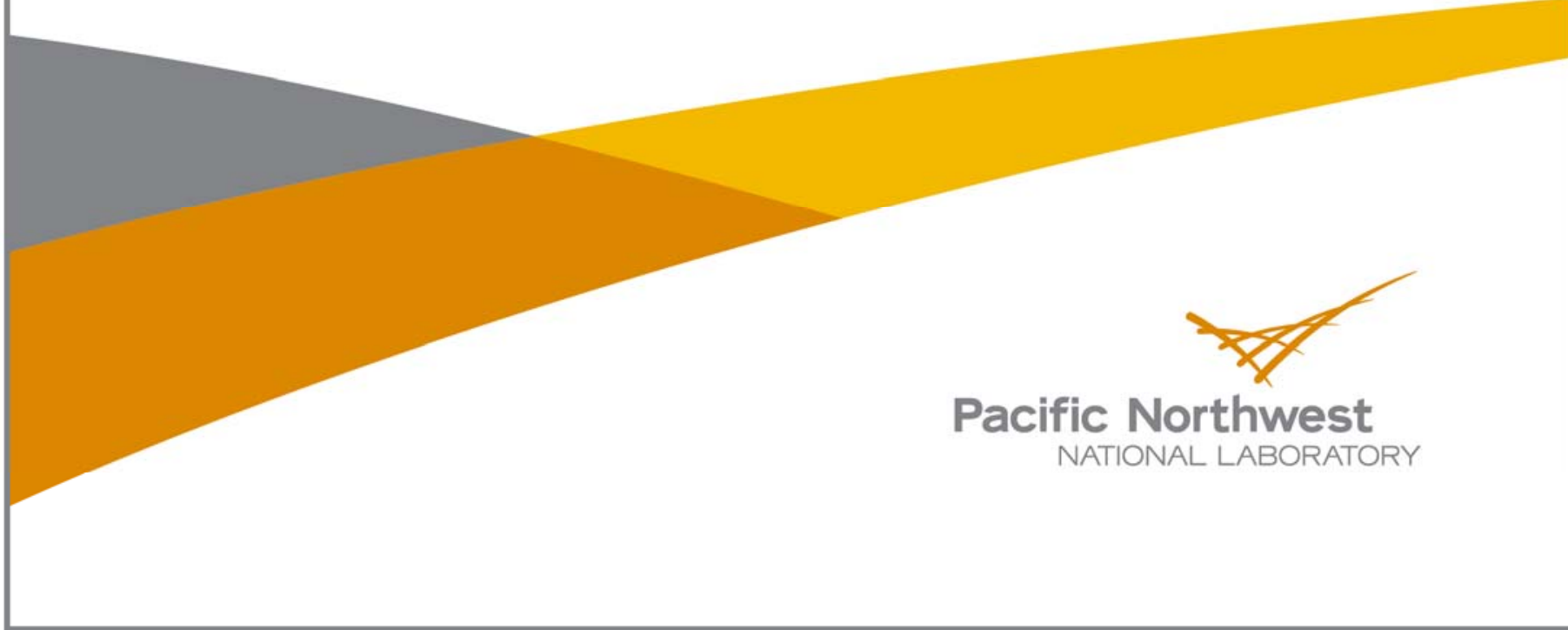




\section{DISCLAIMER}

United States Government. Neither the United States Government nor any agency thereof, nor Battelle Memorial Institute, nor any of their employees, makes any warranty, express or implied, or assumes any legal liability or responsibility for the accuracy, completeness, or usefulness of any information, apparatus, product, or process disclosed, or represents that its use would not infringe privately owned rights. Reference herein to any specific commercial product, process, or service by trade name, trademark, manufacturer, or otherwise does not necessarily constitute or imply its endorsement, recommendation, or favoring by the United States Government or any agency thereof, or Battelle Memorial Institute. The views and opinions of authors expressed herein do not necessarily state or reflect those of the United States Government or any agency thereof.

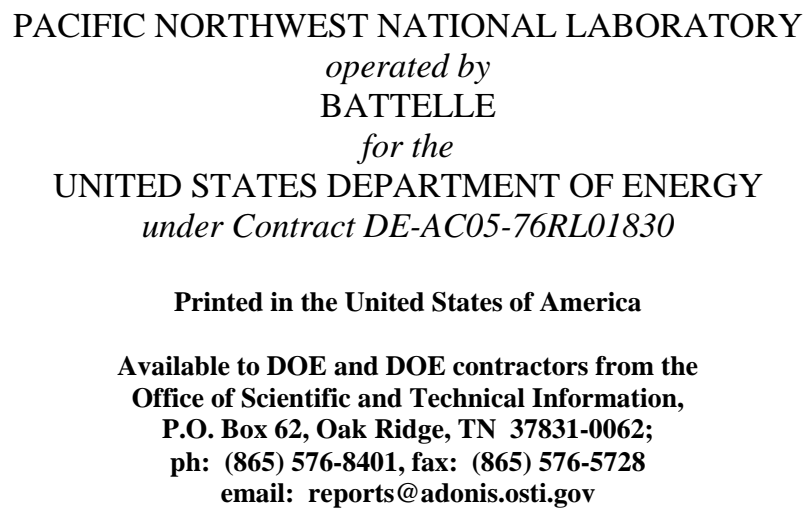

Available to the public from the National Technical Information Service, U.S. Department of Commerce, 5285 Port Royal Rd., Springfield, VA 22161 ph: (800) 553-6847, fax: (703) 605-6900 email: orders@ntis.fedworld.gov

online ordering: http://www.ntis.gov/ordering.htm 
PNNL-19027

Low Probability Tail Event Analysis and Mitigation in the BPA Control Area: Task 1 Report

S Lu, Ph.D.: Senior Research Engineer, Project Manager

YV Makarov, Ph.D.: Chief Scientist - Power Systems

April 2009

Prepared for

U.S. Department of Energy

under Contract DE-AC05-76RL01830

Pacific Northwest National Laboratory

Richland, Washington 99352 


\section{SUMMARY}

This report analyzes what happened during the Electric Reliability Council of Texas (ERCOT) reliability event on February 26, 2008, which was widely reported because of the involvement of wind generation. The objective is to identify sources of the problem, solutions to it and potential improvements that can be made to the system. Lessons learned from the analysis include the following:

1. Large mismatch between generation and load can be caused by load forecast error, wind forecast error and generation scheduling control error on traditional generators, or a combination of all of the above.

2. The capability of system balancing resources should be evaluated both in capacity (MW) and in ramp rate (MW/min), and be procured accordingly to meet both requirements. The resources need to be able to cover a range corresponding to the variability of load and wind in the system, additional to other uncertainties.

3. Unexpected ramps caused by load and wind can both become the cause leading to serious issues.

4. A look-ahead tool evaluating system balancing requirement during real-time operations and comparing that with available system resources should be very helpful to system operators in predicting the forthcoming of similar events and planning ahead.

5. Demand response (only load reduction in ERCOT event) can effectively reduce loadgeneration mismatch and terminate frequency deviation in an emergency situation. 


\section{ACKNOWLEDGEMENT}

The authors gratefully acknowledge the contributions of John Pease, BPA Project Manager, Technology Innovation Group, for his sincere advice and help to the team. 


\section{CONTENTS}

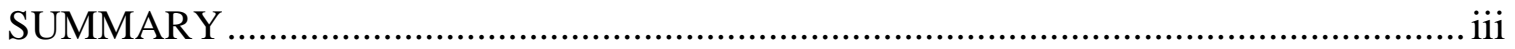

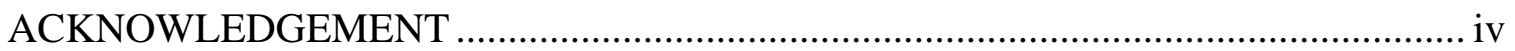

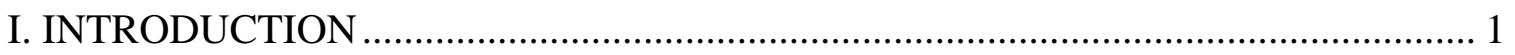

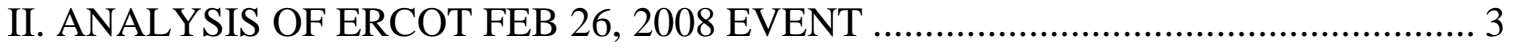

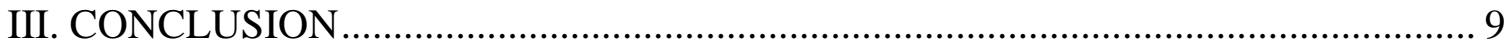

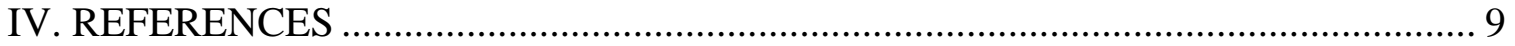




\section{FIGURES}

Figure 1. ERCOT LaaR deployment on Feb 26, 2008 event (from ERCOT Operations Report [1]) ........................................................................................................ 4 Figure 2. 02/26/08 16:00 - 22:00 load and day-ahead load forecast (from ERCOT Operations Report [1]) ……………………………….............................................. 5 Figure 3. 02/26/08 15:00 - 21:00 total wind output, wind forecast in the 16:00 day-ahead resource plan (from ERCOT Operations Report [1]) ……................................................ 6 


\section{INTRODUCTION}

Tail event refers to the situation in a power system when unfavorable forecast errors of load and wind are superposed onto fast load and wind ramps, or non-wind generators falling short of scheduled output, the imbalance between generation and load becomes very significant. This type of events occurs infrequently and appears on the tails of the distribution of system power imbalance; therefore, is referred to as tail events.

With the increasing penetration of intermittent energy sources in the system, including wind and solar, large imbalance is encountered more frequently than ever. Maintaining sufficient balancing reserves, both upward and downward, to match the difference between hourly generation schedule and real-time variable load and intermittent resources, becomes more and more challenging. This project is conducting study on the BPA system historical data, including load, wind generation, non-wind generation and their respective forecasts, to determine the statistical characteristics of combined effects, finding the size, ramp rate and other distributions of tail events. Also, the links between forecast errors, generation schedule control errors, and influential factors such as weather, temperature, wind speed, etc. will be established using a statistical model called Bayes Net. This model can be used in real-time operations to help system operators to predict the chance of large system imbalance/tail events for the next several operation hours, and take actions accordingly.

Task one of this project is analyzing previously reported events when significant amount of wind generation was involved, identifying sources of the problem, solutions to it and potential improvements that can be made to the system.

The following analysis is conducted on an Electric Reliability Council of Texas (ERCOT) reliability event widely reported because of the involvement of wind generation. Analysis specifically on the BPA system events can be added if reports on such events become available. 



\section{ANALYSIS OF ERCOT FEB 26, 2008 EVENT}

On February 26, 2008, the ERCOT system implemented Step Two of its Emergency Electric Curtailment Plan (EECP) during an evening load ramp due to the increasing imbalance between generation and load. The event was widely reported because wind generation falling short of their scheduled output contributed partially in the event. The event time line is listed in detail in ERCOT operations report [1]. Description of the EECP steps can be found in [2]. Main findings on this event that are related to the purpose of this project are summarized in the following.

\subsection{Contributing factors}

There are three contributors to this event: load forecast error during a larger than expected evening load ramp-up from 17:00 to 19:00, wind forecast error as large as 1000 MW during a ramp-down of wind generation from 15:00 to 21:00, and unexpected loss and unavailability of conventional generation. The first two are major causes, with the third one adding complexity to the problem. Collectively these factors led to ERCOT calling on reserve capacity, including Loads acting as a Resource (LaaR) - large industrial and commercial electricity users who have agreed to allow ERCOT to curtail their electricity supply in exchange for economic compensation - to both increase generation and reduce total demand.

\subsection{Services and actions involved}

Main system services and actions involved in the ERCOT operations dealing with the event include the following (listed approximately in the order of actual implementation):

(1) Up Balancing Energy Service

(2) Regulation Up Service

(3) Non-Spinning Reserve Service

(4) Dispatch of Out Of Merit Energy and Capacity

(5) Deployment of Responsive Reserve

(6) Reducing distribution voltage to reduce load

(7) Requesting emergency energy from other systems

(8) Deployment of LaaR.

In ERCOT, each market participant is assigned an obligation to provide ancillary services based on its historical load. Market participants may provide the ancillary services themselves or rely on the ERCOT to acquire the ancillary services through a centralized auction. ERCOT operates the following day-ahead AS markets for the balancing between generation and load: Balancing Energy Service, Regulation Down Service (RgDn), Regulation Up Services (RgUp), Responsive Reserves Services (RRS), Non-Spinning Reserve Services (NSRS), Replacement Reserve Services (RPRS) and Out Of Merit Energy and Capacity (OOME and OOMC) [3]. 
Regulation Down and Regulation Up Services are used to control the power output of Resources in response to a change in system frequency to maintain the system frequency within predetermined limits. RRS is intended to help restore the frequency of the interconnected transmission system within the first few minutes of an event that causes a significant deviation from nominal frequency. RRS is similar to the "spinning reserve service" in other electricity markets. NSRS is a service that is provided through utilization of the portion of off-line generation capacity capable of being synchronized and ramped to a specified output level within thirty minutes (or Load that is capable of being interrupted within thirty minutes) and that is capable of running (or being interrupted) at a specified output level for at least one hour. NSRS may also be provided from unloaded on-line capacity that meets the above response requirements and that is not participating in any other activity, including ERCOT market, self-generation and other energy transaction. RPRS is a service that is procured from Generation resources units planned to be off-line, but which can be brought on-line, and Loads acting as a Resource that are available for interruption. OOMC and OOME are used by ERCOT to provide for the availability of sufficient capacity so that Balancing Energy bids are available to solve capacity insufficiency, Congestion, or other reliability needs.

\subsection{What has helped prominently?}

Demand response implemented in the ERCOT system effectively stopped the fast rampup during the event. Before the deployment of LaaR, load was ramping up very quickly at an unpredicted rate of $\sim 60 \mathrm{MW} / \mathrm{min}$ (refer to Figure 2); after the deployment of LaaR, load almost flattened. With deployment of LaaR, the event lasted less than two hours and no customers lost power involuntarily. Also, according to [1], the response of LaaRs to deployment signal was generally good. Only two failed to deploy within 10 minutes. It appears to be the deployment of LaaR which halted frequency decline and restored ERCOT to stable operation.

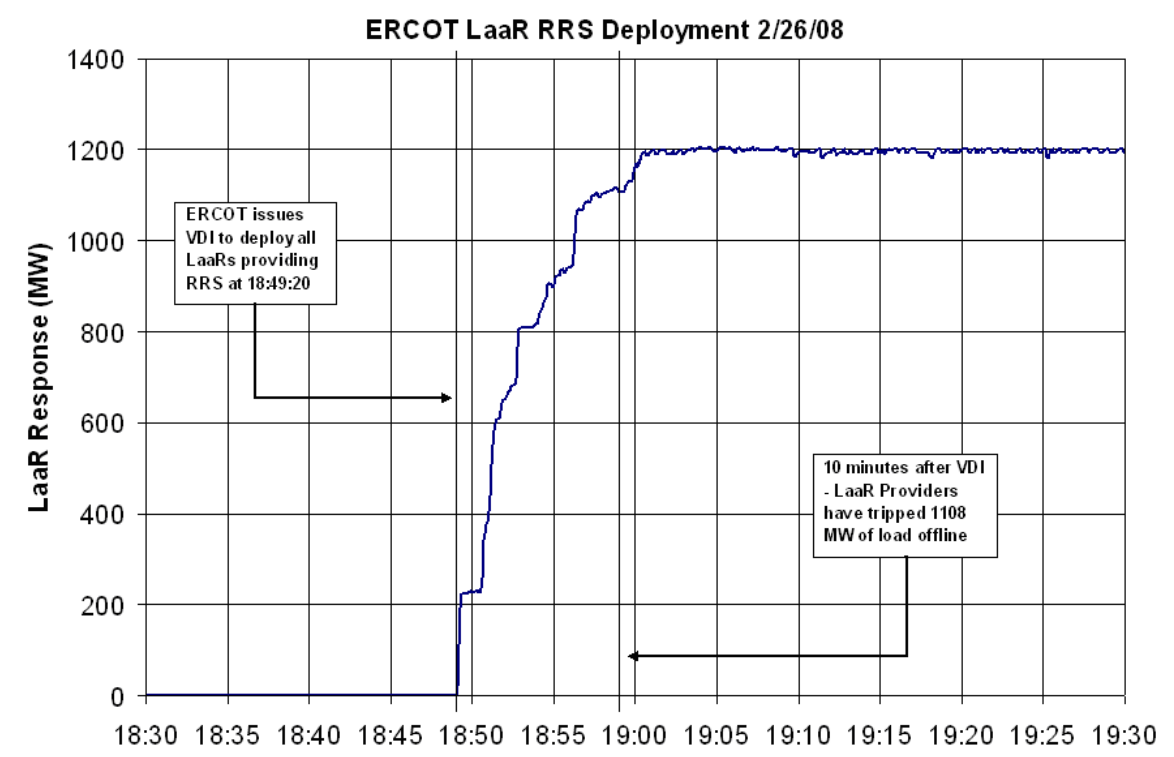

Figure 1. ERCOT LaaR deployment on Feb 26, 2008 event (from ERCOT Operations Report [1]) 


\subsection{What should be improved?}

ERCOT rely on resource plans provided by Qualified Scheduling Entities (QSE's) for its assessment of available capacity. The unpredicted large load ramp and wind forecast error with the resource plan are two major contributors to the event. The combination of these two factors made the procured regulating reserve appear insufficient.

\subsubsection{Load forecast}

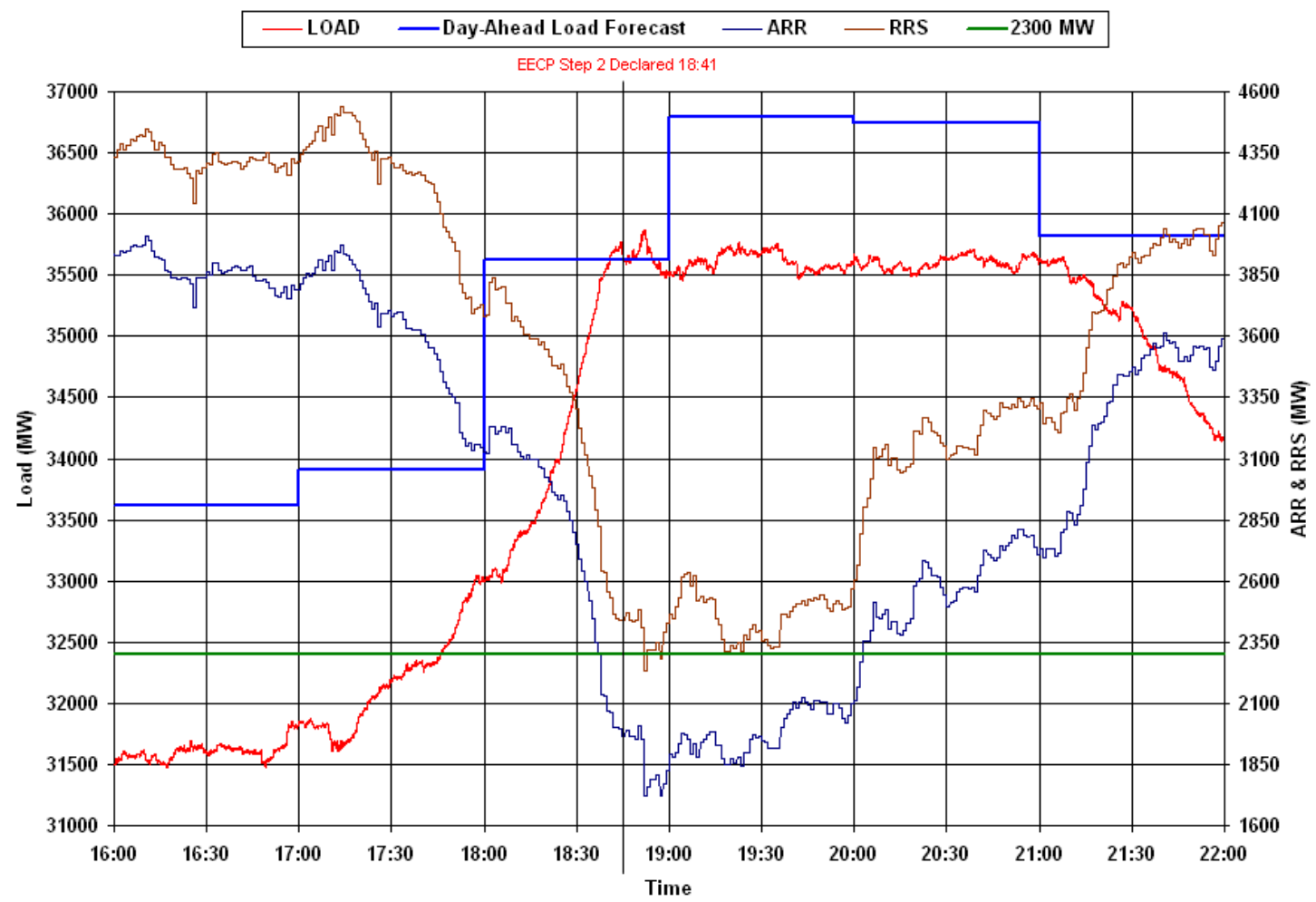

Figure 2. 02/26/08 16:00 - 22:00 load and day-ahead load forecast (from ERCOT Operations Report

[1])

As shown in Figure 2, the day-ahead load forecasts in hour ending at 1800 and hour ending at 1900 are both higher than the actual load. However, the ramp rate predicted in the day-ahead forecast is $\sim 1750 \mathrm{MW} /$ hour (35650 MW at 1900 minus $33900 \mathrm{MW}$ at 1800), while the actual load between 18:00 and 18:41 grew from $\sim 33000 \mathrm{MW}$ to $~ 35550$ MW or an increase of $\sim 2550$ MW in 40 minutes. In real-time operations, the generation schedule may have been adjusted downward to meet the actual load during hours before 1800. Then the combination of unpredicted high load ramp rate during the hour ending at 1900 and the shortage of 900 MW from wind caused difficulties in balancing the system. Associated with the underestimation of combined load and wind ramp rate, ERCOT seemed not to have obtained sufficient regulating reserve for that period. During this period ERCOT exhausted its available regulation up service ( 1000 MW) and up balancing energy service. 


\subsubsection{Wind forecast}

The ERCOT day-ahead resource plan did not forecast the magnitude of the drop in wind energy encountered. As shown in Figure 3, for the hour ending at 1900, the day-ahead forecast is about $1300 \mathrm{MW}$ for wind, while it was actually 400MW during the operation hour. This resulted in a $900 \mathrm{MW}$ shortage of generation from wind resources.

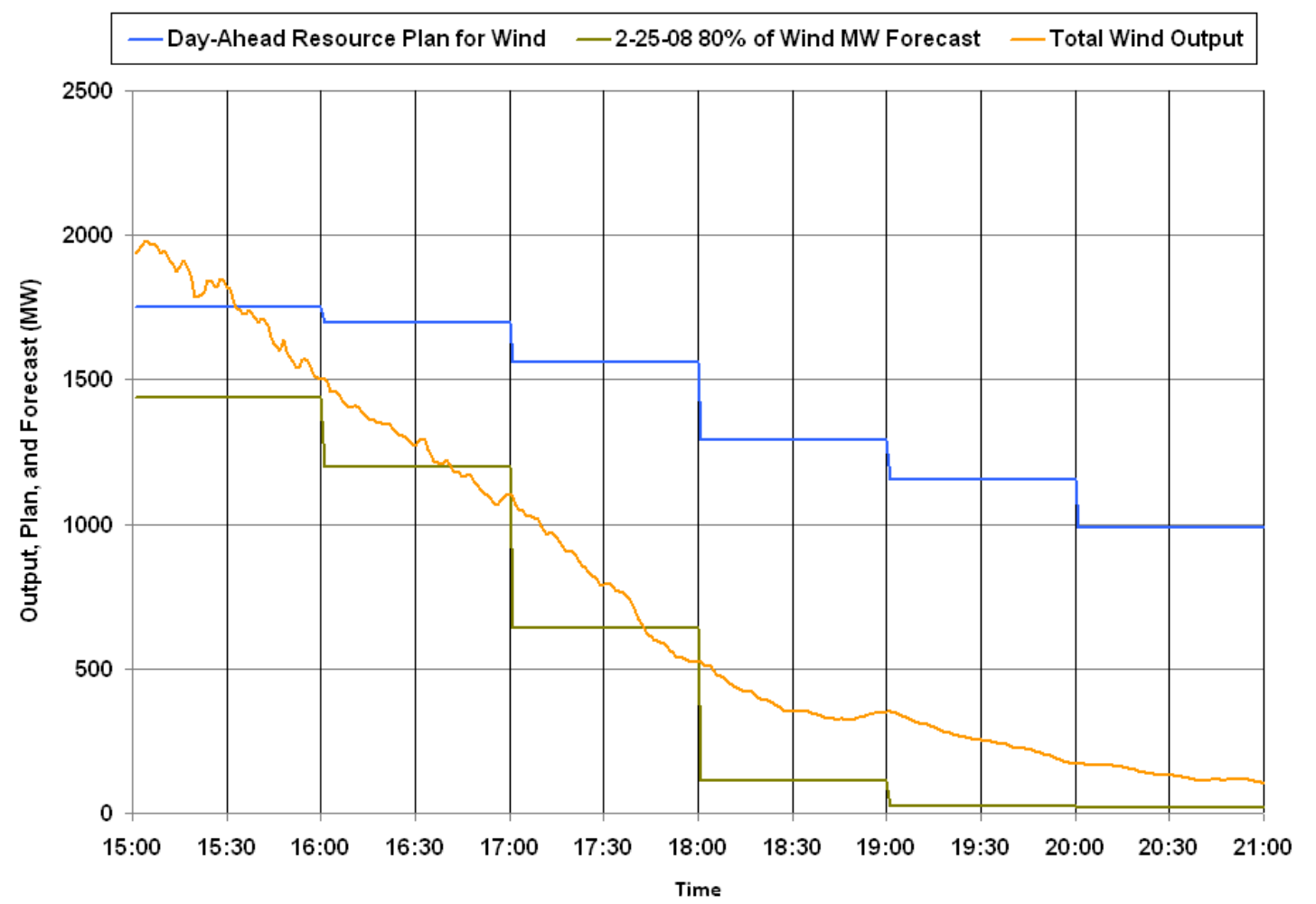

Figure 3. 02/26/08 15:00 - 21:00 total wind output, wind forecast in the 16:00 day-ahead resource plan (from ERCOT Operations Report [1])

However, the $80 \%$ wind forecast that was developed for and will be incorporated into the ERCOT Nodal system shown in green did predict the wind output with good fidelity [1]. When this forecast is incorporated into operation tools that look ahead to evaluate system resource adequacy, the severity of consequences resulting from wind forecast error may be alleviated.

\subsubsection{Prediction of adequacy of regulating reserve}

ERCOT system has Regulation Service to cover the variability of the system, caused by load forecast error, wind power forecast error, uninstructed generation deviations, etc., to maintain system frequency. To evaluate Regulation Service requirements, ERCOT collects monthly historic deployed Regulation Service data. This data is used to calculate average historically deployed Regulation Service for one-minute periods. By calculating the 98.8 percentile of the deployed regulation up and regulation down by hour, ERCOT will estimate the expected needs for similar months [4]. 
It is, therefore, by design that for a certain amount of time the system will be lacking of balancing reserve, or experience load-generation imbalance, because of the exhaustion of available resource. The imbalance can be small and negligible, but it can also get very large and cause intolerable frequency deviation of the system. ERCOT Feb 26, 2008 event is an occasion of the later. In these occasions, it would be of great help if the operators can have a prediction of system imbalance based on forecast and system resource information updated in real time. When the operators are aware of the possible forthcoming event, and amount of shortage in resources, they can prepare ahead of the time to avoid large frequency deviations. A methodology to provide such real-time prediction is described in [5]. 



\section{CONCLUSION}

This report analyzes the Electric Reliability Council of Texas (ERCOT) reliability event on February 26, 2008, which was widely reported because of the involvement of wind generation. The following lessons can be derived from the analysis:

Large mismatch between generation and load can be caused by load forecast error, wind forecast error and generation scheduling control error on traditional generators or a combination of all of the above.

Although usually forecast errors in capacity or MW could cause generation insufficiency in real-time operation, unpredicted ramp rate or $\mathrm{MW} / \mathrm{min}$ can also cause problems, even if the forecasted generation requirement is higher than the actual needed in MW. Therefore, the capability of system balancing resources should be evaluated and prepared both in capacity (MW) and in ramp rate (MW/min), and needs to be able to adjust in a range corresponding to the variability of load and wind in the system, additional to other system uncertainties. This flexibility requirement should be reflected in the scheduling of generation units, as well as the methodology to determine balancing reserves.

Unexpected ramps caused by load and wind can both become the cause of serious issues. Power system operators usually complain about the fast ramps caused by wind power plants. The ERCOT event on Feb 26, 2008 also shows that unexpected fast load ramps can also cause problems.

A look-ahead tool evaluating system balancing requirement during real-time operations and comparing that with available system resources should be very helpful to system operators in predicting the forthcoming of similar events and planning ahead. This tool should take updated information as inputs, including load forecast, wind power forecast, predicted availability of system balancing resources, and then evaluate the capability of system resources to meet system requirements in the next few hours.

Demand response can effectively reduce load-generation mismatch and terminate frequency deviation in an emergency situation. Demand response in the ERCOT event only involved load reduction (LaaR). The response from LaaR effectively flattened the upward ramp of evening load in the ERCOT system during the event, alleviating the generation insufficiency problem and terminated frequency drop. It shows that demand response can be a trustable resource during system emergencies. 



\section{REFERENCES}

[1] ERCOT Operations Report on the EECP Event of February 26, 2008, [Online]. Available:

http://www.ercot.com/meetings/ros/keydocs/2008/0313/07._ERCOT_OPERATIONS_R EPORT_EECP022608_public.doc

[2] ERCOT Event on February 26, 2008: Lessons Learned, [Online]. Available:

http://www.nrel.gov/wind/systemsintegration/pdfs/2008/ela_ercot_event.pdf

[3] ERCOT Protocols - Section 6: Ancillary Services, [Online]. Available:

http://www.ercot.com/content/mktrules/protocols/current/06-

110109.doc\#_Toc244479688

[4] ERCOT Methodologies for Determining Ancillary Service Requirements, [Online]. Available:

http://www.ercot.com/content/meetings/tac/keydocs/2009/1105/12._ROS.ERCOT_Meth odologies_for_Determining_Ancillary_Servic.doc

[5] Shuai Lu, Yuri V. Makarov, Alan J. Brothers, Craig A. McKinstry, Shuangshuang Jin, and John H. Pease, Prediction of Power System Balancing Requirement and Tail Event, IEEE Transmission and Distribution Conference 2010, New Orleans, LA, April 19-22, 2010. Accepted. 